\title{
Time to think about physician wellness in gastroenterology
}

\author{
Subrata Ghosh MD FRCPC FRCP FRCPE
}

\begin{abstract}
A bdominal pain and bloating are common symptoms, even in healthy people (1). However, participation in rotating shift work involving nurses is associated with development of irritable bowel syndrome (IBS) and abdominal pain independent of sleep quality (2). Increasing attention is being devoted to physician wellness because this may impact patient outcomes and health care systems. Sleep deprivation and stress may affect physician performance and well-being. However, too little research has been performed on physician wellness and the demands placed on their life by stress, sleep deprivation and erratic nutrition. The research performed by Wells et al (3), reported in the current issue of the Canadian Journal of Gastroenterology (pages 281-284), on overnight call and IBS is welcome. In a web-based survey, there was no difference in the prevalence of IBS between preclinical and clerkship students and IBS-Quality of Life was not different. Whether this observation is also true for physicians on overnight call requires further study because the level of responsibility of clerkship medical students is different from staff physicians on overnight call.

It is noticeable, however, that the prevalence of IBS in the general population was estimated to be $13 \%$ in women and $5 \%$ of men in the United Kingdom, although the presence of one or more symptoms is much more common (4). Medical students and nurses have a relatively high prevalence of IBS by this yardstick - approximately $20 \%$ or more. Physician wellness is an important but neglected aspect of highquality health care provision (5). Discipline-specific studies are required to understand the impact of the demands of being on call, including overnight call, shift work, erratic nutrition and long work hours, dealing with adverse events, complaints and litigation, with burnout reported in $25 \%$ to $60 \%$ of doctors (6). Physicians also devote inadequate attention to their own wellness, especially in the face of increasing expectations and a culture of patient-centred care. A healthy work environment in health care service requires a balance between the demands placed on physicians and patients, and a personcentred workplace where wellness of health care providers and patients are equally emphasized for the best outcome.

There is little research into physician wellness in gastroenterologists. As a profession, gastroenterology is a demanding, procedurebased discipline, often requiring long work hours, dealing with very sick patients and sleep deprivation while on overnight call (Box 1). The effect of these on gastroenterologists requires research so that effective wellness programs may be designed. The Canadian Association
\end{abstract}

of Gastroenterology and the Canadian Association for Study of the Liver may be well placed to conduct such studies. All four domains of physician wellness may be challenged in gastroenterology, as in many other specialties, but we do not have specific information on many of these, and resident wellness programs and gastroenterologist wellness programs are not well established. Effective, scientifically designed wellness programs, effective mentorship and supportive teamwork are all critical.

\section{BOX 1}

Challenges to physician wellness

Physical: Fatigue, long work hours, demanding procedures, lack of exercise, layout of a hospital, erratic nutrition and hydration.

Mental: Stress, anxiety, depression, lack of sleep, burn-out, providing leadership in a challenging environment, substance abuse.

Social: Lack of leisure, lack of other pursuits, lack of family time, relationship difficulties, feel pressured not to take holidays.

Intellectual: Information overload, lack of time to innovate, unfinished work, medical errors, lack of time to update skills and knowledge, lack of mentorship.

\section{REFERENCES}

1. Heaton KW, Ghosh S, Braddon FEM. How bad are the symptoms and bowel dysfunction of patients with the irritable bowel syndrome? A prospective controlled study with emphasis on stool form. Gut 1991;32:73-9.

2. Nojkov B, Rubenstein JH, Chey WD, Hoogerwerf WA. The impact of rotating shift work on the prevalence of irritable bowel syndrome in nurses. Am J Gastroenterol 2010;105:842-7.

3. Wells M, Roth L, McWilliam M, Thompson K, Chande N. A cross-sectional study of the association between overnight call and irritable bowel syndrome in medical students.

Can J Gastroenterol 2012;26:281-4.

4. Heaton KW, O'Donnell LJ, Braddon FE, Mountford RA, Hughes AO, Cripps PJ. Symptoms of irritable bowel syndrome in a British urban community: Consulters and nonconsulters. Gastroenterology 1992;102:1962-7.

5. Wallace JE, Lemaire JB, Ghali WA. Physician wellness: A missing quality indicator. Lancet 2009;374:1714-21.

6. Editorial. Doctors get ill too. Lancet 2009;374:1653. 


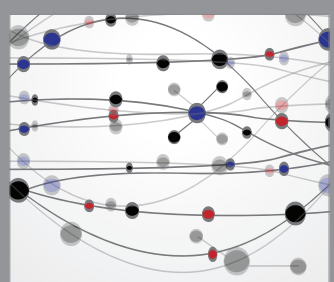

The Scientific World Journal
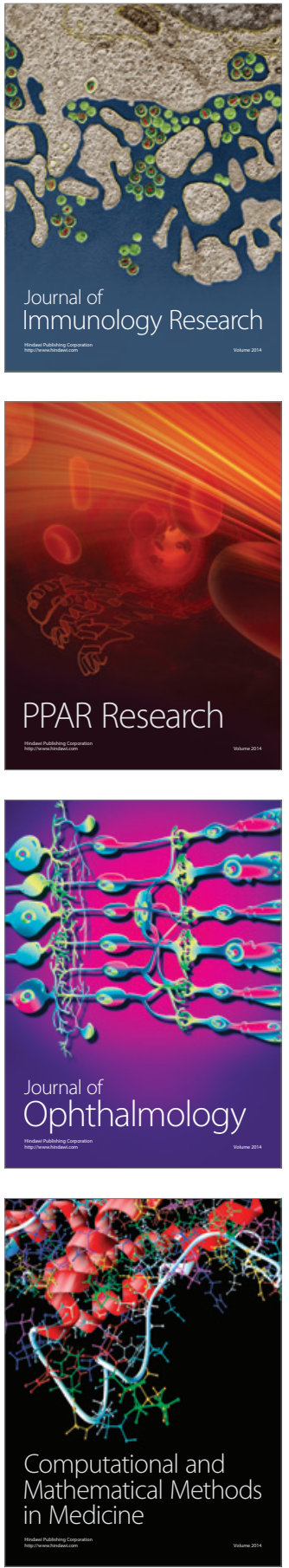

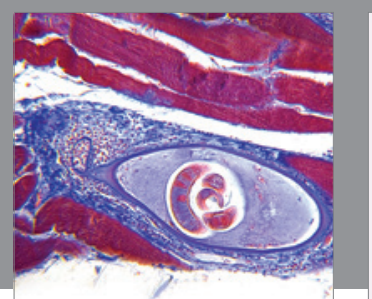

Gastroenterology Research and Practice

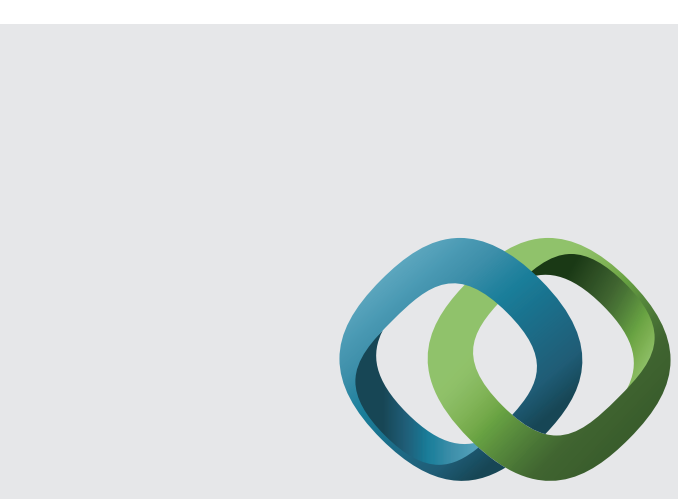

\section{Hindawi}

Submit your manuscripts at

http://www.hindawi.com
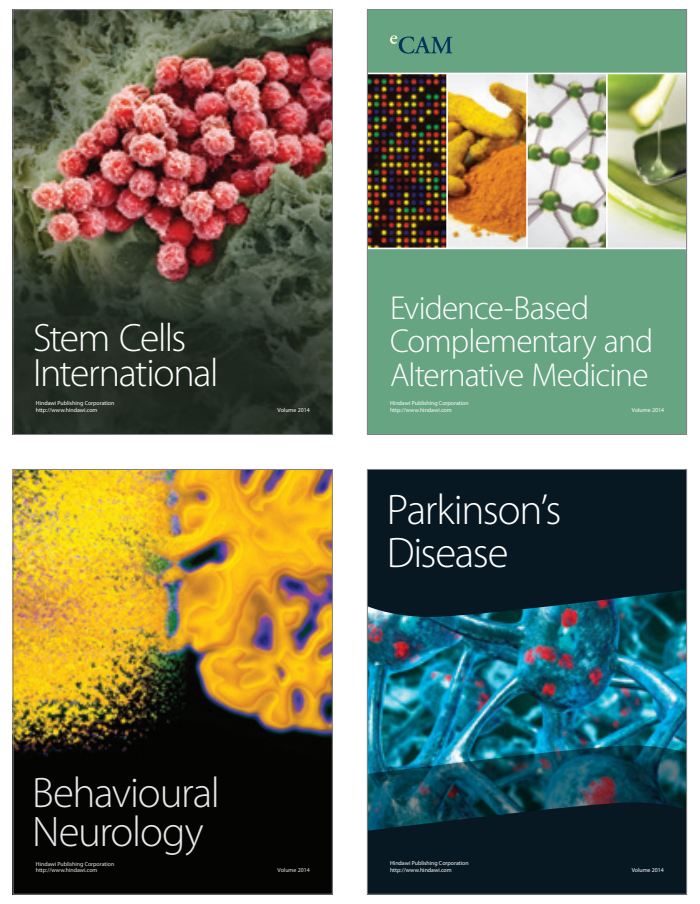
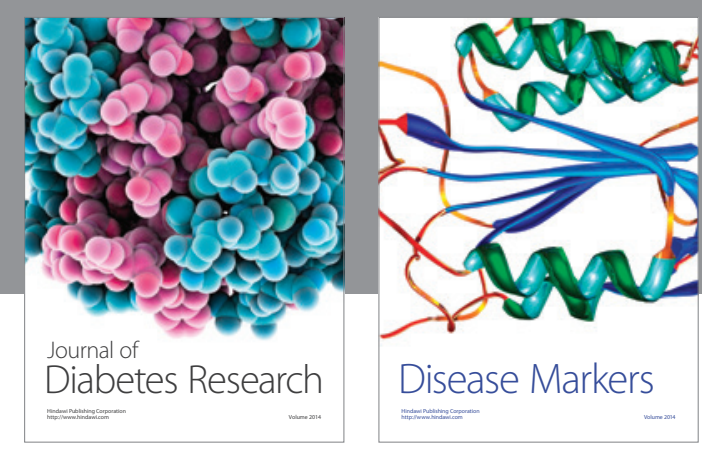

Disease Markers
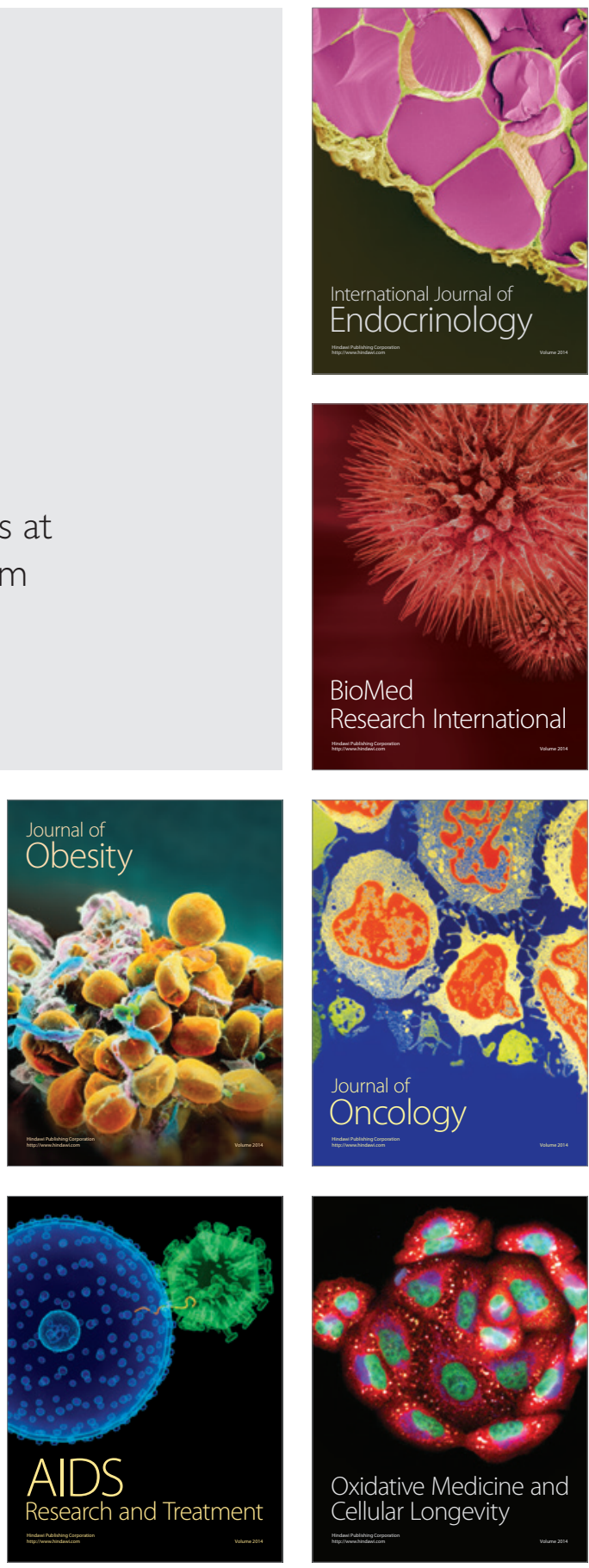